\title{
Implementing a Whole-of-Curriculum Approach to Student Wellbeing
}

\author{
Abi Brooker \\ The University of Melbourne, Melbourne, Australia \\ Meredith McKague \\ The University of Melbourne, Melbourne, Australia \\ Lisa Phillips \\ The University of Melbourne, Melbourne, Australia
}

\begin{abstract}
This article reports and extends on an emerging initiative presented at the 2018 STARS Conference (Auckland, New Zealand). Many universities are invested in student mental health, but solutions can be hindered by concerns about the fit, cost, effectiveness, or sustainability of diverse initiatives. We argue that university staff looking to support student wellbeing should first consider how their specific university contexts can support or diminish wellbeing, and then design initiatives that will fit within supportive systems. This argument is embedded within dynamic systems theory, which considers how relationships between systems can lead to widespread change when any single system changes. We draw on our own experience so far of preparing and developing a whole-of-curriculum approach to wellbeing to demonstrate that a dynamic systems approach means addressing the needs of multiple stakeholders and remaining flexible to changes within surrounding systems.
\end{abstract}

Keywords: Wellbeing; whole-of-curriculum; mental health; student wellbeing; dynamic systems theory.

\section{Introduction}

How can I support students' mental health? is a question facing many academic educators in 21 st century higher education. Recent reports indicate that responding to student distress is a common part of educators' roles (Crawford \& Johns, 2018; Hughes, Panjawni, Tulcidas, \& Byrom, 2018), yet educators feel under-resourced and under-supported when it comes to responding to distress (Brooker, Baik, \& Larcombe, 2017; Hughes et al., 2018). Curriculum-based initiatives that teach students self-care (e.g., Lo, Francis-Cracknell \& Hassed, 2017) or that promote principles of positive psychology (e.g., Field \& Duffy, 2012; Levin, Rixon, \& Keating, 2019) can be effective for reducing distress and promoting wellbeing. Although these initiatives might offer solutions to the question posed above, their success in different university contexts is likely to vary (Sinclair, 2015).

In this article, we propose that the success and sustainability of any initiative, whether embedded within a specific subject curriculum or applied across multiple disciplines, relies on its fit with broader university strategies and policies. Therefore, university staff concerned about student wellbeing need to consider how the specific context of their own university systems might support or diminish their wellbeing approach. For example, an initiative that changes assessment practices is more likely to be successful if it aligns with existing policies regarding assessment and feedback and if it utilises existing resources, than if it creates its own policies or requires new resources. Because the former case is supported by existing university systems and

This work is licensed under a Creative Commons Attribution 4.0 International Licence. As an open access journal, articles are free to use with proper attribution. ISSN: 2205-0795 
draws on practices with which students are already familiar, it is more likely to be efficient and sustainable than the latter. As such, for educators concerned about student wellbeing, we argue that the question posed above is best supported by examining the opportunities within one's own context for sustaining meaningful change. That is, by asking: How can my specific contexts support student mental health?

Our argument is embedded within dynamic systems theory and we draw on our experience preparing for a 'whole-ofcurriculum' approach to student wellbeing as an example of this theory in practice. Dynamic systems theory offers a way of examining the varied relationships with broader university contexts (Haggis, 2008). A whole-of-curriculum approach to wellbeing involves considering how all aspects of the curriculum, from beginning to graduation (including learning objectives, expectations, resources, assessments, teaching approaches, activities, timetabling, outcomes, and content; Kandlbinder, 2014; Watts \& Hodgson, 2015) interact with each other to foster or diminish student wellbeing. This might include spreading out assessments to reduce "pressure points" in semester; providing opportunities for students to learn, practice, and apply key concepts; or ensuring that expectations and learning outcomes are clearly communicated at the beginning. Informed by resources that demonstrate how the curriculum can support wellbeing, such as Baik et al.'s (2017) application of selfdetermination theory to the curriculum, and Crawford, Kift and Jarvis' (2019) discussion of enabling pedagogies, we anticipate that a whole-of-curriculum approach will be effective at increasing student wellbeing.

Given that our aim is to argue for the importance of considering the surrounding contexts, and remaining flexible and iterative in implementation, we do not deem it useful to detail our entire curriculum in this article. For illustrative purposes, our wholeof-curriculum approach is being developed within one accredited undergraduate psychology program at a large metropolitan university in Australia. It includes eight core subjects and 10 elective subjects and is taught by 40 academics and 120 tutors to 2,500 students. We focus our example in this article on the needs of - and changes - to other university systems that are related to our undergraduate program. We do this to demonstrate the substantial amount of attention to local contexts and the flexibility for adaption required, to ensure the success and sustainability of a new initiative for promoting wellbeing.

\section{A Dynamic Systems Approach}

Dynamic systems theory is a developmental theory that considers the relationship between the various components ("systems") of any phenomenon, and how changes in those relationships affect other systems, and ultimately affect the entire phenomenon (e.g., Haggis, 2008; Lerner \& Overton, 2008). The following four principles broadly summarise the theory: (i) any event can be considered to comprise multiple systems (e.g., a learning activity comprises a teacher and a student); (ii) each system has its own aims, needs, resources and means of practice (e.g., the teacher's aims and resources differ from the student's aims and resources); (iii) each system can be defined in terms of its relationship to other systems (e.g., the teacher is not a "teacher" without a "student" to teach, and vice versa); and, given the strong relationships between systems, (iv) substantial change within any one system is likely to influence other systems (e.g., if the teacher should change their aims, then that change will affect the students' activities).

It is worth noting that 'changes' occurring within any system can be diverse, hence different types of change can have different effects on the surrounding systems or broader event. Two contrasting examples can be described as disruptive change and endorsing change. Disruptive change is change that does not align with existing systems. Disruptive change is effective for drawing attention to faults and issues within broader systems. The most pertinent examples of disruptive change are the student protests of the 1960s and 1970s, drawing attention to global issues such as the Vietnam war and local issues such as Indigenous rights (e.g., Murphy, 2015). As Murphy (2015) points out, while this change is effective, it can involve discomfort (including violence and destruction) and confusion (from protestors and from those trying to stop the protests).

Endorsing change is change that aligns with existing systems and supports broader systemic practices. For example, Dill (2014) describes how higher education reform has been slowly but strongly affected by state-level policy changes, such as funding changes that make universities more strategic and competitive in their recruitment of fee-paying students, and patent and licensing changes that have given universities more freedom to profit from research outcomes. These and other policy changes endorsed and enhanced existing practices within the University. Prior to change, these practices were small scale or rare; following change, they became commonplace and expected practices.

These two types of change have very different consequences for those implementing a given change. Disruptive change is more visible, but can set up more challenges, require more energy to implement and lead to more unpredicted outcomes, than 
endorsing change. In contrast, endorsing change can take less effort and be more predictable, but can be more incremental and iterative, can take longer for effect, and can require comprehensive understanding of the systems being changed. Given that the aim of our initiative was not to disrupt surrounding systems, but instead to find ways to draw on surrounding systems to improve outcomes for students, we see our initiative as one that creates endorsing changes. This might mean that our curriculum will take longer to develop and embed, but we anticipate that the change will be more manageable and efficient than a disruptive approach.

From a dynamic systems perspective, regardless of the type of change taking pace, evaluation of that change requires systematic, ongoing measurement of the primary system and surrounding systems. Dooris (2006) points out that most evaluations of initiatives remained focused on those directly affected (i.e., the primary system). He argues that such approaches risk evaluating the initiative as falling short of expectations. In contrast, a dynamic systems approach to evaluation that considers long-term evaluation of primary and surrounding systems allows for a more comprehensive understanding of the impact of the change. For example, in reporting the development of the Healthy Universities UK initiative: a whole-ofuniversity approach to health and climate change, Dooris (2006) identifies students, staff, knowledge, environmental resources, and economic resources as relevant systems. Changes within these systems provided opportunities for impact within the university; they also provided long-term future opportunities for impact outside the university as students graduated and became leaders of their communities. Therefore, evaluations of change need to be ongoing, iterative, and consider broader systems of impact.

Such ongoing evaluation from a dynamic systems perspective can be a difficult task. As Haggis (2008) points out, many of the interactions taking place are likely to be unexpected or invisible, and therefore extremely difficult to include in a formal evaluation. Dooris and Doherty (2010) report the challenges facing long-term changes to whole-of-university approaches, including difficulties providing evidence through evaluation and the difficulties of sustaining cultural change across all relevant systems. Solutions to the former require the type of evaluation that Dooris (2006) describes. Solutions to the latter include regular communication of the initiative and its successes to members within each system (Dooris \& Doherty, 2010). Such communication is not easily documented in traditional empirical approaches to evaluation. In our project, we attend to both issues raised by Dooris and Doherty (2010), ensuring pathways for ongoing evaluation and regular communication across university systems.

\section{Implications of the Dynamic Systems Approach for University-Based Initiatives}

Dynamic systems theory has four implications for university-based initiatives of student mental health. First (Implication 1A in the figure), it highlights the importance of identifying other systems that might affect or be affected by student mental health. For example, responding to distressed students is a common and emotionally difficult part of teaching in higher education (Brooker et al., 2017; Hughes et al., 2018), therefore any reduction or increase to the prevalence or severity of students' distress is likely to influence teaching experiences. Further, reductions or increases in student distress, and availability of resources, are likely to impact the work load and effectiveness of university counselling services (e.g., Stallman, 2012). The first task for us, then, was to identify systems that were likely to be affected by our whole-of-curriculum approach.

Second (Implication 1B), dynamic systems theory highlights the importance of identifying how those systems might affect the initiative. This implication is particularly pertinent for systems that can impede or enhance the success and sustainability of an initiative. For example, development of online counselling resources will be most effective when supported by an effective programming team in collaboration with learning designers and content experts. Our third task, then, was to identify surrounding university systems that could support - or diminish - our whole-of-curriculum approach.

Third (Implication 1C), dynamic systems theory highlights the importance of identifying how those systems might be affected by the initiative. Identifying such change beforehand can mean that systems can be better prepared and experience optimal outcomes. For example, changes to curriculum can lead to positive outcomes if teachers are prepared, supported, and have good strategies in place for working with the change (e.g., Hassed, De Lisle, Sullivan, \& Pier, 2009). Teachers who are not prepared, or who have little time to learn new approaches, are likely to feel overwhelmed and burdened by the change (e.g., Brooker et al., 2017). Counselling teams who find themselves overburdened and unable to meet the demand for services have met this burden by developing diverse online resources that can help alleviate students' stress while awaiting appointments (Inglis \& Cathcart, 2018). Our second task, then, was to identify how each identified system might be affected. 
Fourth (Implication 2), dynamic systems theory highlights the importance of continual reassessment and flexibility of the relationship between the initiative and surrounding systems. Given Haggis's (2008) and Dooris' (2006) arguments above about the challenges evaluating a dynamic system, it seems pertinent that any initiative adopting a dynamic systems approach must remain open to the idea that systems will change, and the initiative and surrounding systems will change, and this will have varying effects on the success and sustainability of the initiative. Our final task then, is to create a baseline understanding (reported here and elsewhere; Brooker et al., forthcoming; Brooker \& McKague, 2019); and to take an iterative approach that allows for further adaptation and evaluation.

Figure 1 shows how these implications have been applied to our experience. The figure outlines the principles of dynamic systems theory on the left-hand side, the implications of those principles for universities (numbered 1A, 1B, 1C, and 2), and aspects of our project as examples of those implications on the right-hand side. For others wanting to consider a dynamic systems approach to their own initiative, the right-hand section of this figure can be adapted to their own context.

\section{Figure 1}

Implications of Dynamic Systems Theory for Embedding a Wellbeing Initiative at University

\begin{tabular}{|c|c|c|c|c|c|}
\hline Principles of dynamic- & Implications for embedding & \multicolumn{4}{|c|}{ Example questions from our initiative } \\
\hline $\begin{array}{l}\text { 1. Systems are } \\
\text { separate from } \\
\text { each other }\end{array}$ & & Students & $\begin{array}{l}\text { Teaching } \\
\text { staff }\end{array}$ & $\begin{array}{c}\text { External } \\
\text { Bodies }\end{array}$ & $\begin{array}{l}\text { Central } \\
\text { University } \\
\text { programs }\end{array}$ \\
\hline $\begin{array}{l}\text { 2. Systems are } \\
\text { related to each } \\
\text { other }\end{array}$ & & \multicolumn{4}{|c|}{$\begin{array}{l}\text { - How might each system support the initiative? } \\
\text { - How might each system conflict with the } \\
\text { initiative? }\end{array}$} \\
\hline $\begin{array}{l}\text { 3. Relationships } \\
\text { define each system }\end{array}$ & & \multicolumn{4}{|c|}{$\begin{array}{l}\text { - How might the initiative endorse / support } \\
\text { each system? } \\
\text { - What outcomes / changes do we anticipate for } \\
\text { each system? }\end{array}$} \\
\hline $\begin{array}{l}\text { 4. Changes to one } \\
\text { system can change } \\
\text { everything }\end{array}$ & & \multicolumn{4}{|c|}{$\begin{array}{l}\text { - How is each system likely to change? } \\
\text { - How might change affect } 1 \mathrm{~A} \& 1 \mathrm{~B} \text { ? } \\
\text { - What other systems are likely to become } \\
\text { important? }\end{array}$} \\
\hline
\end{tabular}

\section{Applying Dynamic Systems Implications to Prepare a Whole-of-Curriculum Approach to Wellbeing}

As shown in Figure 1, the implications of a dynamic systems approach inform our project in multiple ways. We first identify the University systems that are related to our whole-of-curriculum approach to wellbeing, as per Implication $1 \mathrm{~A}$ in Figure 1. We identify four systems and justify each of those relationships below: The student cohort, the teaching cohort, Universitywide programs, and external disciplinary bodies. We then identify how each system might affect and be affected by the initiative, as per Implications 1B-C in Figure 1. We also develop an approach by allowing for flexibility and continuing reassessment, as per Implication 2 in Figure 1. In this article, we summarise our initial "baseline" measures of two systems (the student cohort and the teacher cohort), and how changes to other surrounding systems (University-wide programs and external bodies) have already created opportunities for change and iteration within our initiative.

\section{The Student Cohort}

Perhaps not surprisingly, the primary system of our initiative is our student cohort. Any initiative addressing student wellbeing is likely to identify this group as a key stakeholder. Students are the people who engage with the curriculum, so are most likely to be affected by changes to the curriculum. Amid reports of high prevalence and severity of distress at students at our University 
(Larcombe et al., 2016), and our own research indicating diverse experiences of distress and wellbeing among our students (Brooker et al., forthcoming), we share the concern of other academics for student wellbeing. Our student cohort comprises approximately 2,500 undergraduate students with international and domestic backgrounds, enrolled in one of three undergraduate degrees (Bachelor of Arts, Science, or Biomedicine).

How students might affect the initiative: As the primary group engaging with the curriculum, students' perceptions of the curriculum will ensure either its sustainability or need for change. As such, it is important that we remain vigilant of students' perceptions of the curriculum.

How students might be affected by the initiative: If our initiative is successful, we anticipate a reduction in student distress, an increase in student wellbeing, and an increase in student perceptions of the program. If our initiative is not successful, we will see reductions or no change in these three indicators.

A baseline understanding of the student experience: Our preliminary measures for students include two online surveys and a series of focus groups. The first survey invited all students in the School to report about their experiences of wellbeing and distress. The survey had 697 respondents and is reported elsewhere (Brooker et al., forthcoming). In that survey, most students reported moderately-high levels of wellbeing and varied levels of distress. Although mean distress levels were lower than reported elsewhere, the prevalence of mild distress suggests that this is an issue worth attention within the School. We are in the process of publishing these data elsewhere and will examine changes or stability in distress and wellbeing levels after instigating changes in the School, next year.

Our second survey $(n=60)$ and focus groups $(n=19)$ focused on the learning experiences of undergraduate students. Students offered generally positive feedback about the existing curriculum structure, but also welcomed a curriculum that could better support their learning of statistics and academic writing, and that could offer more variety of psychology sub-disciplines such as mental health and resilience. This feedback gives us clear guidance on content changes to make within the curriculum. We have reported findings from this initial survey to the School Academic Programs Committee and will use this baseline to report changes or stability in the student experience as we implement change.

\section{The Teaching Cohort}

Any change to curriculum will involve training and support to academic and tutor cohorts. Our 120 tutors are the primary facilitators of the curriculum, and as such they are considered the "face of the subject" by many students. They also make regular decisions about the curriculum and are therefore likely to be affected by widespread changes. Most tutors are Masters and/or PhD students. They are comprehensively trained in class management, assessment, and principles of good teaching prior to each semester. During semester, they attend six tutor briefings, teach six pre-designed lab classes, mark assessments and provide feedback to students. Our 40 academic educators take on more senior teaching roles that involve more administration but less individual contact with students, such as curriculum design, subject coordination, and lecturing.

How teaching staff might affect the initiative: Teaching staff who feel confident in the curriculum changes, who understand why changes are occurring, and who can adapt to any changes, will be supportive of the initiative. Teaching staff who do not feel confident or who do not understand the purpose of the change are less likely to support the change. As such, it is important that we are aware of staff concerns and can offer training and resources when needed.

Further, as with other University departments, our School committees regulate and monitor major activities, including curriculum development. Because committees are the main forums of communication among staff, any changes to curriculum must be presented, discussed and approved at the committee level, and any changes to committee structure and process ultimately affect opportunities for curriculum change. For example, earlier this year, the School revised its committee structure to include a teaching and learning committee. This committee of teaching specialists and tutors meets once a month and reports to the Academic Programs Committee and School Executive. The committee has become a key platform for discussing issues regarding curriculum and teaching practices. As such, it contributes to the impact of this project by offering a reporting body for ongoing evaluations of our project and future projects affecting teaching and learning.

How teaching staff might be affected by the initiative: In the short term, the effect on staff will be related to learning new approaches to curriculum. Some will view this as skill building, others might view it as extra effort and time. If we achieve an increase in student wellbeing a and decrease in the experience of distress, then the effect for teachers will be a reduction in the 
time and energy dedicated to supporting distressed students, and teachers will have more energy to create more engaging learning experiences.

A baseline understanding of the tutor experience: Our initial online survey for teaching staff focused on the experiences of 58 undergraduate tutors. Their responses painted a concerning picture in which tutors were the first point of contact for students in need, regardless of whether they were the most appropriate contact or not. Most respondents reported regular experiences of students disclosing mental health issues and requesting special assistance. Some respondents reported experiences of students becoming distressed or demanding. Although tutors were keenly aware of the School's guidelines for responding to students in distress, they were less aware of University resources and referral pathways, and much less aware of support services for staff. A large proportion were interested in training and resources to support their mental health and the mental health of their students. Their feedback highlights a need for clearer supports, and mental health training, for tutors. It also indicated that addressing student mental health might have positive outcomes on the tutor experience. We have reported findings from this initial survey to the School Academic Programs Committee and at a Faculty symposium for discussion (Brooker $\&$ McKague, 2019).

Following on from the tutors' interest in mental health training, we have invested in a within-School Mental Health First Aid (MHFA) trainer and offered regular sessions of MHFA training to tutors outside of semester teaching. The demand for this training is high. To date, 24 tutors have completed MFHA training, with another 34 on a waiting list. Tutors who have completed the training have unanimously, but anecdotally, reported its high value in their teaching practice and personal lives. We will formally evaluate the effect of this training on tutor experiences next year and will continue to offer at least three training sessions per year to tutors.

\section{University-Wide Programs}

University Chancellery often present strategic guides, values, and University-wide programs that inform teaching and learning. For example, Chancellery work to ensure that five educational objectives guide University teaching: Challenge, Inquiry, Application, Collaboration and Self-Direction. ${ }^{1}$ Any whole-of-curriculum approach within our university therefore must endorse and work alongside thee values. Further, issues of student wellbeing and mental health are already being addressed by University services such as University counselling and psychological services (CAPS). Any initiative that we develop is likely to affect, and be affected by, resources and initiatives provided by CAPS.

How University-wide programs might affect the initiative: By aligning with University-wide programs, our initiative will represent one more system that endorses and enhances those programs. As such, the values and policies expressed across the University will be essential for guiding decisions about our initiative. For example, our curriculum will be disseminated using the online learning systems used across the University. If programs or policies change, our curriculum will need to adjust as well.

There are two programs that have taken place in the past 12 months that have required adjustments of the initiative, both of which have been beneficial. First, the Flexible Academic Programming project (FlexAP; https://provost.unimelb.edu.au/digitallearning) is a University initiative led by Chancellery that aims to enhance teaching quality, provide more flexible study options, and make more effective use of existing infrastructure and resources. FlexAP offers support to revisions of large undergraduate subjects (>300 students), and revisions of the curriculum structure and teaching approach of whole programs. Given that the eight core subjects of our undergraduate psychology program each have $>500$ students, these are prime candidates for FlexAP support. As such, any decision to review our curriculum program is currently more likely to be sustained and supported by the University if it aligns with the aims of FlexAP.

FlexAP has allowed us to consider the aims of our project with the larger values of the University in mind, without changing the direction of our whole-of-curriculum approach to wellbeing. For example, at a practical level, implementation of the wholeof-curriculum approach will be separated out into first year, then second year, then third year subjects, to align with FlexAP funding opportunities. At a conceptual level, the focus on flexible study options provides a new lens for thinking about students' autonomous motivation and decision-making.

\footnotetext{
${ }^{1}$ https://melbourne-cshe.unimelb.edu.au/resources/categories/teaching-and-learning/teaching-in-practice/the-melbourne-way
} 
Second, CAPS (the University counselling and psychological service) recently developed an internally-focused resource that advises staff on processes for supporting student mental health, including referral pathways and support services for staff. This resource achieves one of the needs identified by tutors. As such, rather than create a similar resource for the School, we have disseminated this resource to tutors and full-time teaching staff. Tutors and staff have reported anecdotally that the resource has been useful for them, especially when dealing with students in distress. We will evaluate the effect of this resource for tutors next year.

How University-wide programs might be affected by the initiative: As we are developing changes that endorse and enhance other University systems, we envisage that our curriculum will have minimal impact on other systems beyond promotion. Our dissemination of the CAPS resource, for example, has led to a wider awareness of CAPS programs among our teaching staff. Our involvement with FlexAP is an endorsement of that initiative. In the long-term, if our curriculum is successful in increasing student resilience and wellbeing, we anticipate reducing pressures on these other systems (e.g., reducing demand on student counselling services and special consideration processes; encouraging other departments to consider curriculum approaches to wellbeing).

\section{External Disciplinary Bodies}

The accredited psychology undergraduate program is regulated by two external disciplinary bodies: the Australian Psychology Accreditation Council (APAC) and the Australian Qualifications Framework (AQF).

How external disciplinary bodies might affect the initiative: Universities offering accredited psychology programs must satisfy regular accreditation assessments. Therefore, any revisions or changes to the program curriculum must remain aligned with the standards outlined by AQF and APAC. This does not mean that the external bodies have a limiting effect on the curriculum. Instead, they can be used to draw attention to and support for the curriculum. For example, our recent accreditation assessment necessitated a whole-of-School curriculum audit of undergraduate and postgraduate programs. As this accreditation focuses on APAC standards and graduate competencies, it does not specifically have the wellbeing lens of our project. However, this audit has created opportunities for whole-of-School discussions about changes to the curriculum, including the purpose and structure of the program. Our whole-of-curriculum approach to wellbeing can make meaningful contributions to those discussions, moving forward.

How external disciplinary bodies might be affected by the initiative: Currently, it is difficult to see how our curriculum approach might affect external disciplinary bodies. Consistent with the fourth implication of the dynamic systems approach, it is possible that changes to the relationship between our School and thee bodies will not be quickly apprarent. It is therefore important that we continue to monitor the relationship between our curriculum and thee bodies as we implement our initiative.

\section{Discussion}

In this article, we argue that there is no one answer to the question "how do we support student mental health?", because the answer will vary depending on the context and culture of the university. As such, those invested in supporting student mental health will be well placed to develop their own answer by investigating their own university systems.

Taking a developmental systems approach, we argue that the success and sustainability of any initiative, whether embedded within a specific subject curriculum or applied across multiple disciplines, relies on its fit with broader university strategies and policies. We draw on our own experience of developing and planning for a whole-of-curriculum approach to student wellbeing to demonstrate what a dynamic systems approach of exploring one's own university context might involve. We do this with the hope that our example will help academics in other contexts identify the systems that are likely to affect the success and sustainability of their own initiatives.

Four implications of the dynamic systems approach guided our experience: (i) identifying relevant surrounding systems, (ii) identifying how those systems are likely to be affected by the initiative, (iii) identifying how those systems are likely to affect the initiative, and (iv) ensuring flexibility in approach. Part of that approach involves remaining aware and responsive to changes within surrounding systems. These four implications are not necessarily new or unfamiliar to readers - certainly previous approaches to student mental health have considered the impact on students and tutors, for example, Hassed et al.'s (2009) development of the ESSENCE program; and others have considered adapting resources to new platforms, such as Inglis and Cathcart's (2018) discussion of counselling services developing online resources to meet demands. What we offer is a 
framework embedded in theory about change (Lerner \& Overton, 2008). We anticipate that the four implications that we highlight will offer a framework for readers wanting to implement change and support student wellbeing.

The list of systems that are affected by our whole-of-curriculum approach to wellbeing as provided in this article is not exhaustive. Once implemented, the curriculum will affect and be affected by other systems including assessment policies, IT support, professional/administrative support, student administration processes, and funding opportunities. We will pay closer attention to these systems as they become more directly involved with the initiative. This is consistent with the approach recommended by Dooris (2006) and Haggis (2008), who both identify that while it is not feasible to attend to all systems, it is useful to recognize when and how various surrounding systems might become more prominent. Further, this is consistent with the dynamic systems approach of regularly revisiting relationships across systems, to identify challenges and opportunities for growth (Dooris \& Doherty, 2010).

We have made the choice not to report our whole-of-curriculum approach to wellbeing because we are conscious that learning is contextual and a good curriculum can take many forms, depending on the aims, resources, setting, and target audience of the course. A curriculum that works in one setting might not work in another. For example, a program designed for 2,500 youngadult students in a metropolitan setting will require a different set of activities, resources, and expectations, from a program designed for 50 students, or middle-adult students, or students in a rural setting. For readers seeking advice about whole-ofcurriculum approaches to wellbeing, we recommend exploring other existing resources that have already been mentioned above, such as those developed by Baik et al. (2016) and Crawford et al. (2019). For those considering starting initiatives to address wellbeing, we have more direct advice: to be vigilantly aware of the many surrounding university systems that can support or thwart the success of any initiative, and to use that information to develop sustainable and effective initiatives that support student wellbeing.

\section{References}

Baik, C., Larcombe, W., Brooker, A., Wyn, J., Allen, L., Brett, M., ... \& James, R. (2017). Enhancing student mental wellbeing: A handbook for academic educators. The University of Melbourne: Australia. http://unistudentwellbeing.edu.au/framework/

Brooker, A., Baik, C., \& Larcombe, W. (2017, June 27-30). Understanding academic educators' work in supporting student wellbeing. In Proceedings of HERDSA Conference, Sydney.

Brooker, A., McKague, M, Grech, L., Raisbeck, P., \& Philips, L. (forthcoming) How are distress and wellbeing related? A university example. Journal of College Student Development.

Brooker, A., \& McKague, M. (2019). Student mental health: the tutor experience. Invited Presentation at the MDHS Teaching and Learning Symposium, University of Melbourne: Carlton, Australia.

Crawford, N. L., \& Johns, S. (2018). An academic's role? Supporting student wellbeing in pre-university enabling programs. Journal of University Teaching \& Learning Practice, 15(3), 2. https://ro.uow.edu.au/jutlp/vol15/iss3/2

Crawford, N., Kift, S., \& Jarvis, L. (2019). Supporting student mental wellbeing in enabling education. In A. Jones, A. Olds, \& J. G. Lisciandro (eds.) Transitioning Students in Higher Education: Philosophy, Pedagogy and Practice. Routledge.

Dill, D. D. (2014). Public policy design and university reform: Insights into academic change. In Reforming higher education (pp. 21-37). Springer.

Dooris, M. (2006). Healthy settings: Challenges to generating evidence of effectiveness. Health Promotion International, 21(1), 55-65. https://doi.org/10.1093/heapro/dai030

Dooris, M., \& Doherty, S. (2010). Healthy Universities: Current activity and future directions-findings and reflections from a national-level qualitative research study. Global Health Promotion, 17(3), 06-16. https://doi.org/10.1177\%2F1757975915601037

Field, R., \& Duffy, J. (2012). Better to light a single candle than to curse the darkness: Promoting law student well-being through a first year law subject. QUT Law Review, 12, 133. https://doi.org/10.5204/qutlr.v12i1.233

Haggis, T. (2008). 'Knowledge Must Be Contextual': Some possible implications of complexity and dynamic systems theories for educational research. Educational Philosophy and Theory, 40(1), 158-176. https://doi.org/10.1111/j.1469$\underline{5812.2007 .00403 . \mathrm{X}}$

Hassed, C., De Lisle, S., Sullivan, G., \& Pier, C. (2009). Enhancing the health of medical students: Outcomes of an integrated mindfulness and lifestyle program. Advances in Health Sciences Education, 14(3), 387-398. https://doi.org/10.1007/s10459-008-9125-3

Hughes, G., Panjawni, M., Tulcidas, P., \& Byrom, N., Dr. (2018). Student Mental Health: The role and experiences of academics (Rep.). Student Minds. 
Inglis, B., \& Cathcart, K. (2018). Online Counselling Support in Australian and New Zealand Universities. Journal of the Australian and New Zealand Student Services Association, 26(2), 4735. https://doi.org/10.30688/janzssa.2018.11

Kandlbinder, P. (2014). Constructive alignment in university teaching. HERDSA News, 36(3), 5.

Larcombe, W., Finch, S., Sore, R., Murray, C. M., Kentish, S., Mulder, R. A., ... \& Williams, D. A. (2016). Prevalence and socio-demographic correlates of psychological distress among students at an Australian university. Studies in Higher Education, 41(6), 1074-1091. https://doi.org/10.1080/03075079.2014.966072

Lerner, R. M., \& Overton, W. F. (2008). Exemplifying the integrations of the relational developmental system: Synthesizing theory, research, and application to promote positive development and social justice. Journal of Adolescent Research, 23(3), 245-255. https://doi.org/10.1177\%2F0743558408314385

Levin, E., Rixon, A., \& Keating, M. (2019). How can a 'Sense of Belonging' inform your teaching strategy? Reflections from a core business unit. A Practice Report. Student Success, 10(2). 71-78. https://doi.org/10.5204/ssj.v10i2.1307

Lo, K., Francis-Cracknell, A, \& \& Hassed, C. (2017). A health enhancement program for physiotherapy students: A mixed methods pilot study. New Zealand Journal of Physiotherapy, 45(3), 143-153.

Murphy, K. (2015). 'In the Backblocks of Capitalism': Australian Student Activism in the Global 1960s. Australian Historical Studies, 46(2), 252-268. https://doi.org/10.1080/1031461X.2015.1039554

Sinclair, A. (2015). Possibilities, purpose and pitfalls: Insights from introducing mindfulness to leaders. Journal of Spirituality, Leadership and Management, 8(1), 3-11.

Stallman, H. M. (2012). University counselling services in Australia and New Zealand: Activities, changes, and challenges. Australian Psychologist, 47(4), 249-253. https://doi.org/10.1111/j.1742-9544.2011.00023.x

Watts, L., \& Hodgson, D. (2015). Whole curriculum mapping of assessment: Cartographies of assessment and learning. Social Work Education, 34(6), 682-699. https://doi.org/10.1080/02615479.2015.1048217

\section{Please cite this article as:}

Brooker, A., McKague, M., \& Phillips, L. (2019). Implementing a whole-of-curriculum approach to student wellbeing. Student Success, 10(3), 55-63. https://doi.org/10.5204/ssj.v10i3.1417

This article has been peer reviewed and accepted for publication in Student Success. Please see the Editorial Policies under the 'About' section of the Journal website for further information.

Student Success: A journal exploring the experiences of students in tertiary education

(c) (1) This work is licensed under a Creative Commons Attribution 4.0 International Licence. As an open access journal, articles are free to use with proper attribution. ISSN: 2205-0795 